\title{
PERANCANGAN DAN IMPLEMENTASI POIN NILAI OTOMATIS BERDASARKAN BENDERA WASIT BERBASIS WIRELESS PADA PERTANDINGAN ROBOT
}

\author{
DESIGN AND IMPLEMENTATION OF AUTOMATIC VALUE POINTS BASED ON \\ WIRELESS BASED WIRELESS ON ROBOT MATCHES
}

\author{
Puji Widodo**1, Iwan Fitrianto Rahmad $^{2}$, Alfa Saleh ${ }^{3}$ \\ ${ }^{1}$ Jurusan Teknik Informatika Universitas Potensi Utama \\ ${ }^{2,3}$ Dosen Jurusan Teknik Informatika Fakultas Universitas Potensi Utama \\ 1,2,3 Universitas Potensi Utama, K.L Yos Sudarso KM 6.5 No. 3A Tanjung Mulia - Medan \\ E-mail: *1uji1widodo@gmail.com, ${ }^{2}$ iwanfitrah@yahoo.com, ${ }^{3}$ alfasoleh1@gmail.com
}

\begin{abstract}
Abstrak
Dalam Pertandingan Robot, sebuah robot dituntut untuk dapat bergerak menyusuri lapangan pertandingan yang telah ditetapkan. Robot didesain sedemikian rupa sehingga memiliki kemampuan menjelajahi lapangan pertandingan dan menyelesaikan tugas-tugas yang diberikan dengan kecepatan tinggi. Untuk itu tentunya membuat Wasit dan Juri perlombaan harus lebih jeli dalam melakukan penilaian perlombaan, agar perlombaan - perlombaan robot dapat berjalan dengan baik. Dengan demikian dibutuhkan alat yang dapat membantu Wasit dan Juri dalam melakukan penilaian yaitu bendera wasit berbasis nirkabel. Perancangan proyek akhir ini merupakan implementasi dari bendera wasit berbasis nirkabel yang digunakan pada pertandingan robot. Bendera wasit ini menggunakan perangkat bluetooth hc-05 sebagai media pengirim data dan arduino nano sebagai mikrokontroler. Hasil akhir dari perencanaan proyek akhir ini adalah bendera wasit dapat mengirim data secara langsung pada server dan hasil pertandingan dapat ditampilkan pada aplikasi papan skor server.
\end{abstract}

Kata Kunci : Bendera Wasit, Nirkabel, Bluetooth, Robot, Pertandingan

\begin{abstract}
In a Robot Match, a robot is required to be able to move down a predetermined playing field. The robot is designed in such a way that it has the ability to explore the playing field and accomplish the tasks assigned at high speed. For that course makes the Referee and Jury race should be more observant in conducting race assessments, so that the race - the robot race can run well. Thus a tool that can help the Referees and Judges in the assessment of the wireless-based referee flag. The design of this final project is an implementation of wireless-based referee flags used in robot matches. The referee flag uses bluetooth hc-05 device as data sender and arduino nano as microcontroller. The final result of this final project planning is the referee flag can send data directly on the server and the results of the match can be displayed on the server scoreboard application.
\end{abstract}

Keywords : Flag of Ref, Wireless, Bluetooth, Robot, Match 


\section{PENDAHULUAN}

Teknologi komputer, terutama robotika di masa sekarang sudah menjadi bagian penting dalam kehidupan manusia. Robot adalah peralatan eletro-mekanik atau biomekanik, atau gabungan peralatan yang menghasilkan gerakan yang otonomi maupun gerakan berdasarkan gerakan yang diperintahkan. Robot dalam beberapa hal dapat menggantikan peran manusia, hal ini terlihat pada robot-robot yang diterapkan dalam berbagai bidang seperti industri, kesehatan, pertahanan, pertanian, penelitian, permainan, dan lain-lain. Maka saat ini semakin sering perlombaan perlombaan robot diadakan di tingkat pelajar SMA sederajat ataupun Mahasiswa yang bertujuan untuk mengasah kemampuan dalam berkreativitas untuk memadukan kemampuan elektronika, software serta mekanik robotika.

Salah satu penilaian pada perlombaan robot adalah kecepatan robot dalam mencapai titik perhitungan (checkpoint) dan garis akhir dalam waktu yang telah ditentukan, misalnya pada perlombaan robot pengikut garis (Line Follower Robot), robot ini mampu mengikuti garis yang sesuai dengan kriteria jalur garis yang telah ditetapkan dengan kecepatan tinggi. Hal ini tentunya membuat Wasit dan Juri perlombaan harus lebih jeli dalam melakukan penilaian perlombaan, agar perlombaan - perlombaan robot dapat berjalan dengan baik. Sehingga penulis tertarik untuk merancang Bendera Wasit yang dapat mempermudah dalam penilaian Wasit dan Juri.

Berdasarkan uraian diatas maka penulis berkesimpulan untuk mengambil judul "Perancangan dan Implementasi Poin Nilai Otomatis berdasarkan Bendera Wasit Berbasis Wireless pada Pertandingan Robot"

\section{METODE PENELITIAN}

\subsection{Studi Literatur}

Penulisan ini dimulai dengan studi kepustakaan yaitu proses pengumpulan bahan-bahan referensi baik dari buku, artikel, jurnal, makalah, maupun situs internet mengenai Arduino, Visual Basic .NET, Bluetooth HC-05 serta beberapa referensi lainnya untuk menunjang pencapaian tujuan penelitian.

\subsection{Proses Penelitian}

Tujuan dari penelitian adalah mencoba untuk membuat Bendera Wasit yang dapat mengirimkan penilaian ke papan skor secara otomatis dan mempermudah Juri dan Wasit dalam melakukan penilaian, dengan memanfaatkan koneksi Bluetooth yang dapat mengirimkan data dari jarak jauh

Pada tahap ini dilakukan dengan mempelajari teori dasar yang mendukung penelitian, pencarian dan pengumpulan data-data yang dibutuhkan. Untuk mengumpulkan data yang dibutuhkan, maka penulis memakai teknik :

1. Pengumpulan data, yaitu mengumpulkan informasi dan mempelajari tentang sistem cara kerja alat.

2. Analisa permasalahan, untuk mengetahui dan menentukan batasan-batasan sistem sehingga dapat menentukan cara yang paling efektif dalam penyelesaian permasalahan.

3. Perancangan alat, setelah menganalisa permasalahan, selanjutnya dilakukan pengumpulan data dan perancangan alat dengan menggunakan model perancangan alat yang telah ditetapkan.

4. Implementasi alat, membuat alat berdasarkan rancangan alat yang telah dibuat sesuai dengan data yang ada.

5. Uji coba alat, menguji alat yang telah dibuat, untuk mengetahui letak kesalahan dan memperbaikinya.

6. Dokumentasi, membuat laporan dari pengerjaan yang telah dilakukan. 
Langkah - langkah yang diperlukan untuk mencapai tujuan perancangan dapat dilihat pada gambar 1. di bawah ini:

\section{Target :}

Perancangan dan Implemantasi Bendera Wasit Menggunakan Mikrokontroler Arduino Nano
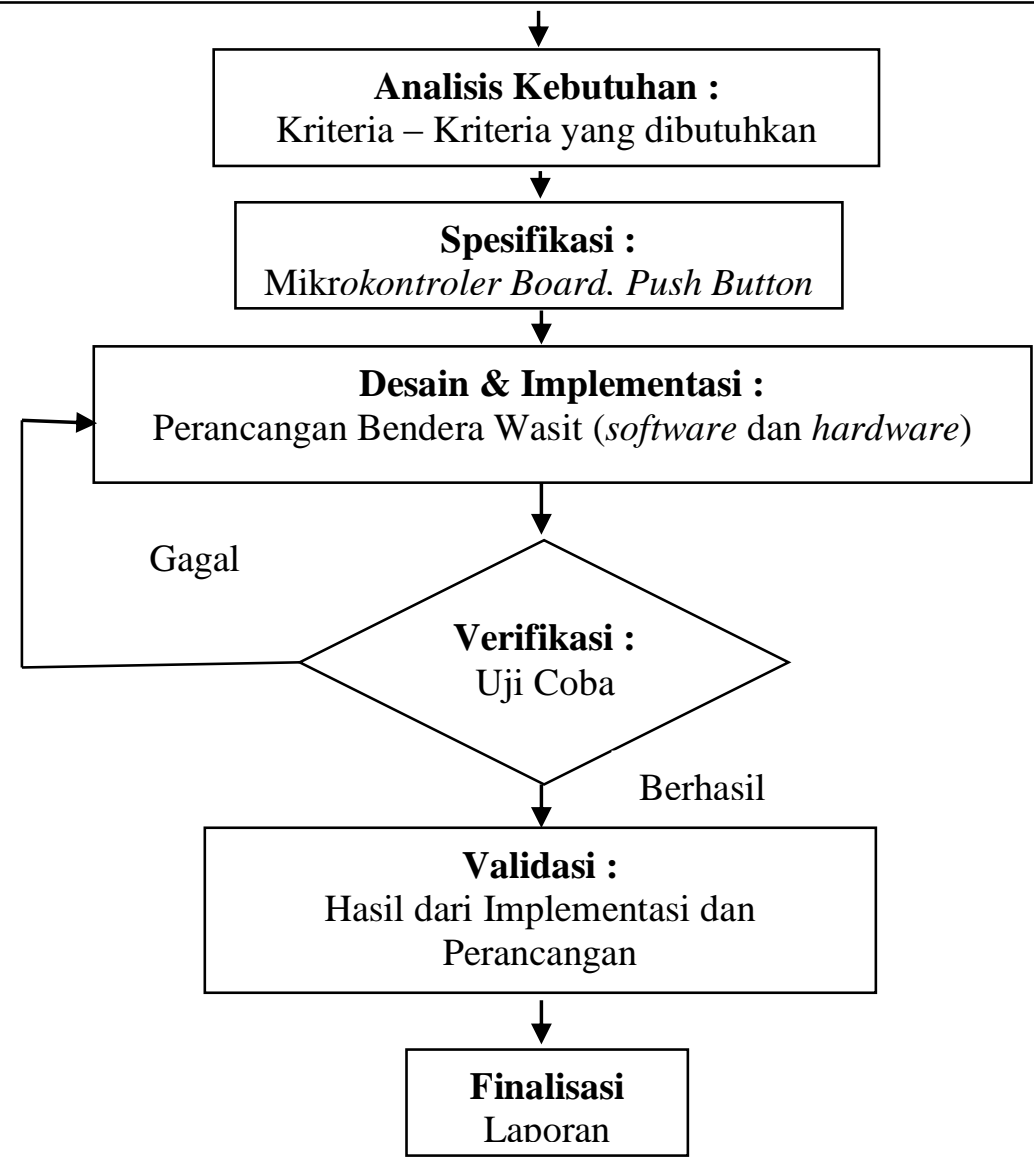

Gambar 1. Prosedur Perancangan

\subsection{Diagram Blok Komponen}

Secara garis besar, Perancangan dan Implementasi Poin Nilai Otomatis berdasarkan Bendera Wasit Berbasis Wireless pada Pertandingan Robot ini terdiri dari Mikrokontroler Arduino, tombol, buzzer, LCD 16x2, tombol, arduino nano dan Bluetooth HC-05.

Diagram blok dari Perancangan dan Implementasi Poin Nilai Otomatis berdasarkan Bendera Wasit Berbasis Wireless pada Pertandingan Robot diditunjukkan pada gambar 1. berikut ini: 


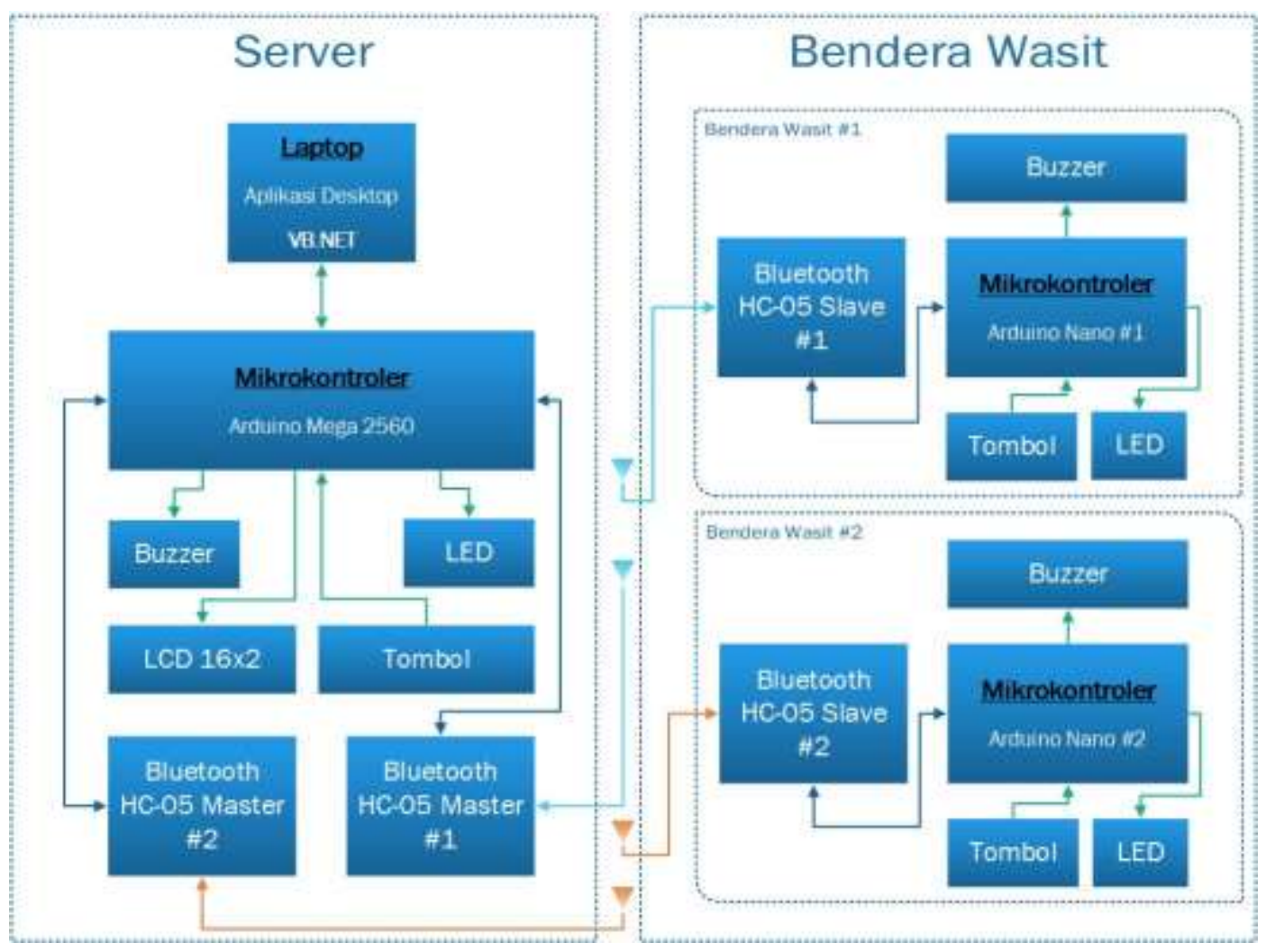

Gambar 2. Diagram Blok Komponen

1. Laptop merupakan sebagai media Output yang berfungsi untuk menampilkan Aplikasi Desktop dan data dari Server

2. Mikrokontroler Arduino Mega 2560 merupakan pusat kendali dari seluruh rangkaian.

3. LCD 16x2 sebagai tampilan media data secara hardware.

4. Tombol berfungsi sebagai Input pada Mikrokontroler Arduino.

5. Bluetooth HC-05 \#1 dan Bluetooth HC-05 \#2 merupakan penghubung komunikasi antara Server dan Bendera Wasit.

6. Buzzer berfungsi memberikan info berupa suara.

7. LED berfungsi sebagai indikator.

\subsection{Perancangan}

Perancangan Perancangan dan Implementasi Poin Nilai Otomatis berdasarkan Bendera Wasit Berbasis Wireless pada Pertandingan Robot ini terdiri dari beberapa bagian bagian, yaitu perancangan secara elektronik, perancangan secara mekanik dan perancangan software interface.

\subsubsection{Perancangan Bluetooth HC-05 Pada Arduino Mega 2560}

Bluetooth HC-05 pada Arduino Mega 2560 berfungsi sebagai penerima data pada Server yang dikirim dari dua Bendera Wasit. Dalam perancangan ini, Bluetooth HC-05 digunakan sebagai media pengirim data antara Bendera Wasit dan Server yang selanjutnya data diolah pada Aplikasi Desktop Server. Rangkaian Bluetooth HC-05 yang terhubung pada pin Arduino dapat dilihat pada gambar 3. berikut: 


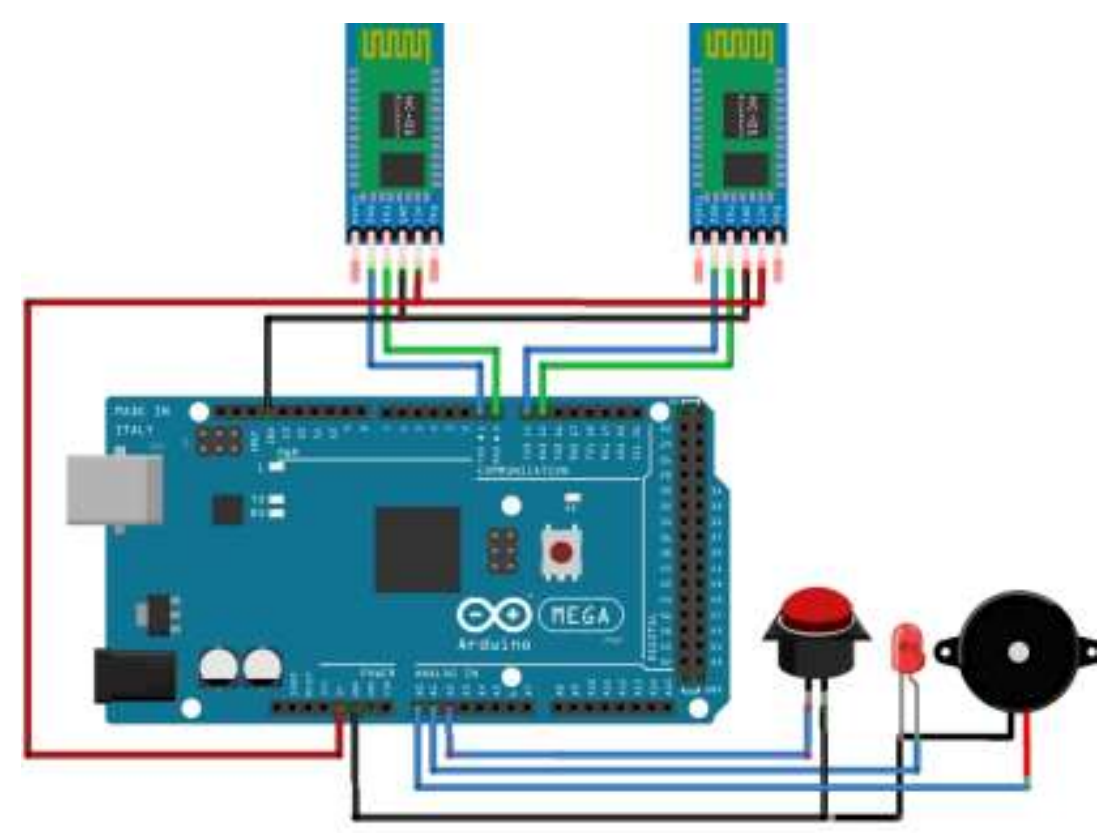

Gambar 3. Rangkaian Bluetooth HC-05 yang dirancang pada Arduino Mega 2560 Server Bendera Wasit

\subsubsection{Perancangan Bluetooth HC-05 Pada Arduino Nano}

Bluetooth HC-05 pada Arduino Nano berfungsi sebagai pengirim data dari Bendera Wasit ke Server. Dalam perancangan ini, Bluetooth HC-05 digunakan sebagai media pengirim data antara Bendera Wasit dan Server yang selanjutnya data diolah pada Aplikasi Desktop Server. Rangkaian Bluetooth HC-05 yang terhubung pada pin Arduino dapat dilihat pada gambar 4. berikut:

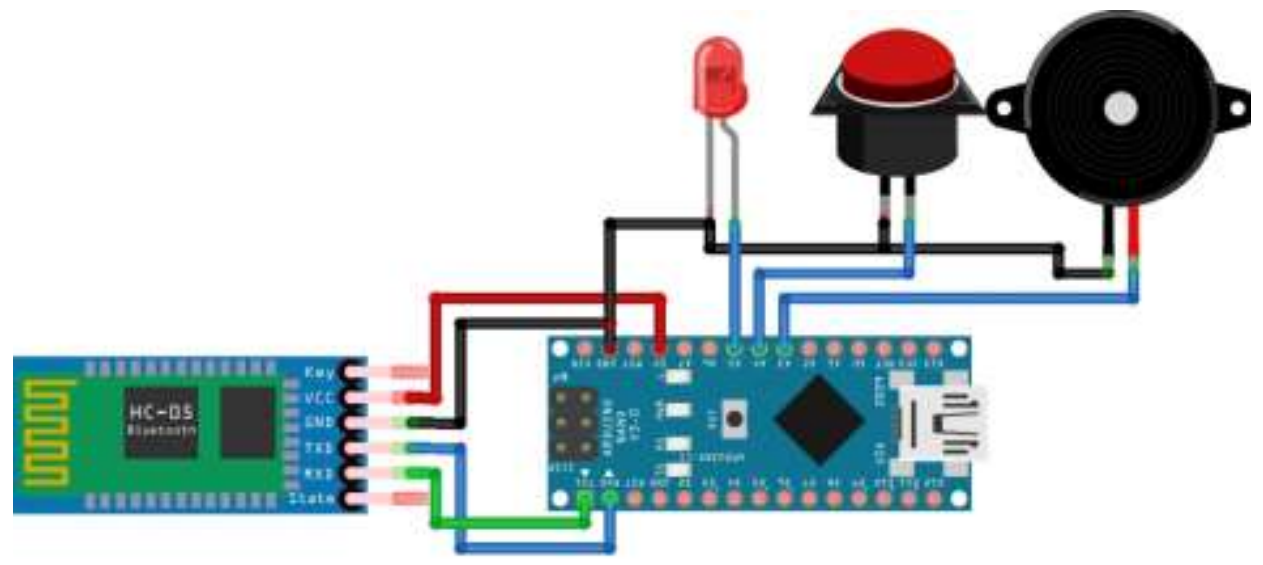

Gambar 4. Rangkaian Bluetooth HC-05 yang dirancang pada Arduino Nano Bendera Wasit

\subsubsection{Perancangan Mekanik}

Desain mekanik perancangan Bendera Wasit Berbasis Wireless yaitu untuk meletakan tombol (push button) pada stik Bendera. Bahan yang digunakan pada stik bendera adalah pipa pvc ukuran 3/4 inch dengan begitu dapat dengan mudah dalam perancangan Bendera Wasit. Dimensi stik Bendera Wasit dengan panjang sebesar $40 \mathrm{~cm}$, pemasangan tombol disesuaikan dengan tangkai 
(handle) Bendera yang seperti pada umumnya. Berikut adalah gambar dari perancangan Bendera Wasit Berbasis Wireless seperti di bawah ini : 


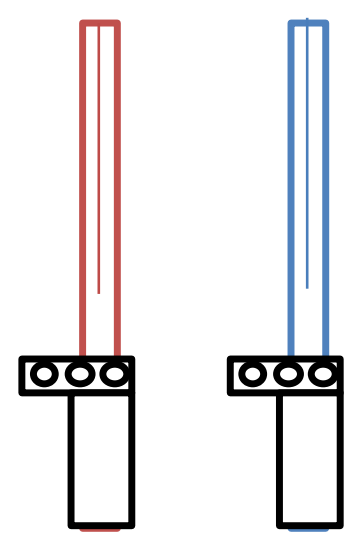

Gambar 5. Perancangan Mekanik

\subsubsection{Perancangan Perangkat Lunak}

Perancangan software pada Bendera Wasit berbasis Wireless dimulai mendesain tampilan form untuk alat yang akan dibuat. Setelah itu akan dirancang pembuatan program untuk alat yang akan dibuat. Perancangan tampilan pada program Visual Basic 2010 bertujuan untuk menggambarkan sketsa desain tampilan program yang akan dibuat sebagai interface kepada pengguna aplikasi. Berikut rancangan tampilan form untuk perancangan Bendera Wasit berbasis Wireless:

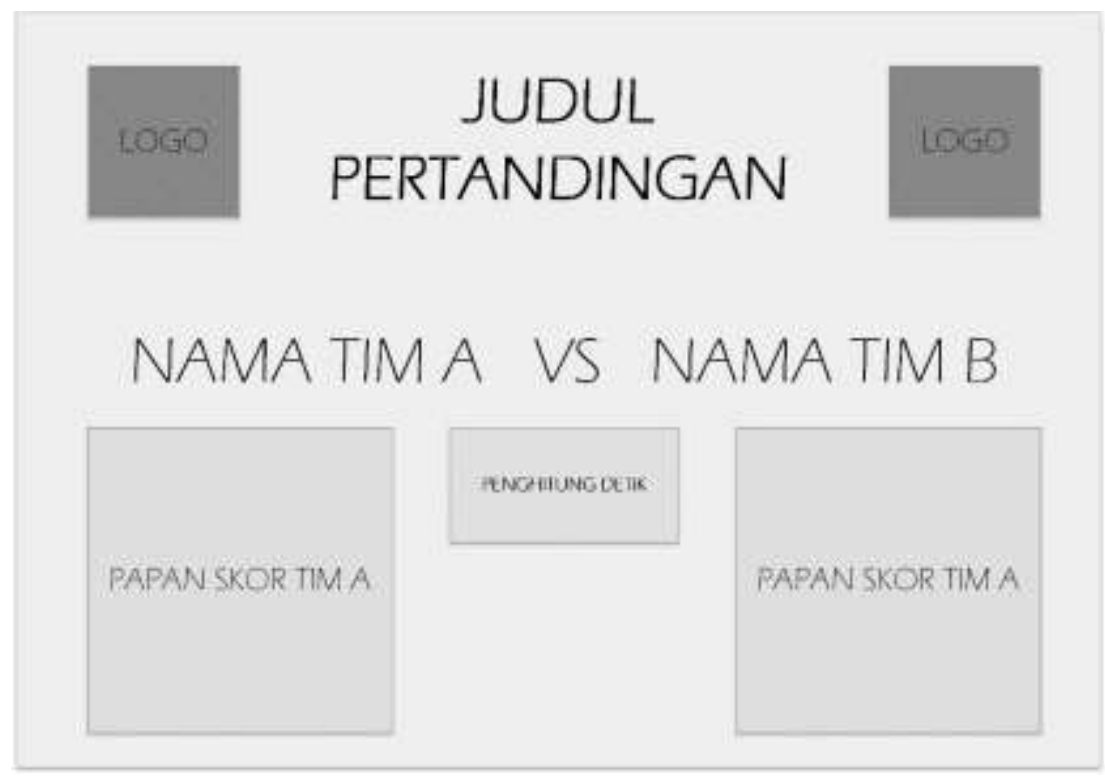

Gambar 6. Perancangan Perangkat Lunak

Pada gambar 6, tampilan yang akan dibuat dapat menampilkan beberapa perintah untuk melakukan koneksi dan data hasil Pertandingan Robot. Dalam perancangan aplikasi terdapat info koneksi yang menerangkan apakah sudah terkoneksi dengan perangkat atau tidak dan indikator data diterima dari perangkat ke aplikasi. 


\section{HASIL DAN PEMBAHASAN}

Berikut ini akan dijelaskan tentang tampilan hasil dari Perancangan dan Implementasi Poin Nilai Otomatis berdasarkan Bendera Wasit Berbasis Wireless pada Pertandingan Robot. Adapun hasil dari pengujian yang dilakukan adalah perangkat elektronik yang dibuat atau dirancang dan diprogram dengan menggunakan aplikasi Arduino IDE.

\subsection{Tampilan Utama}

Tampilan utama merupakan halaman utama yang akan muncul apabila program dijalankan dan telah melakukan konfigurasi pertandingan. Pada halaman ini dapat menampilkan data poin yang dikirim oleh mikrokontroler secara realtime. Tampilan Menu Utama dapat dilihat pada gambar 7.

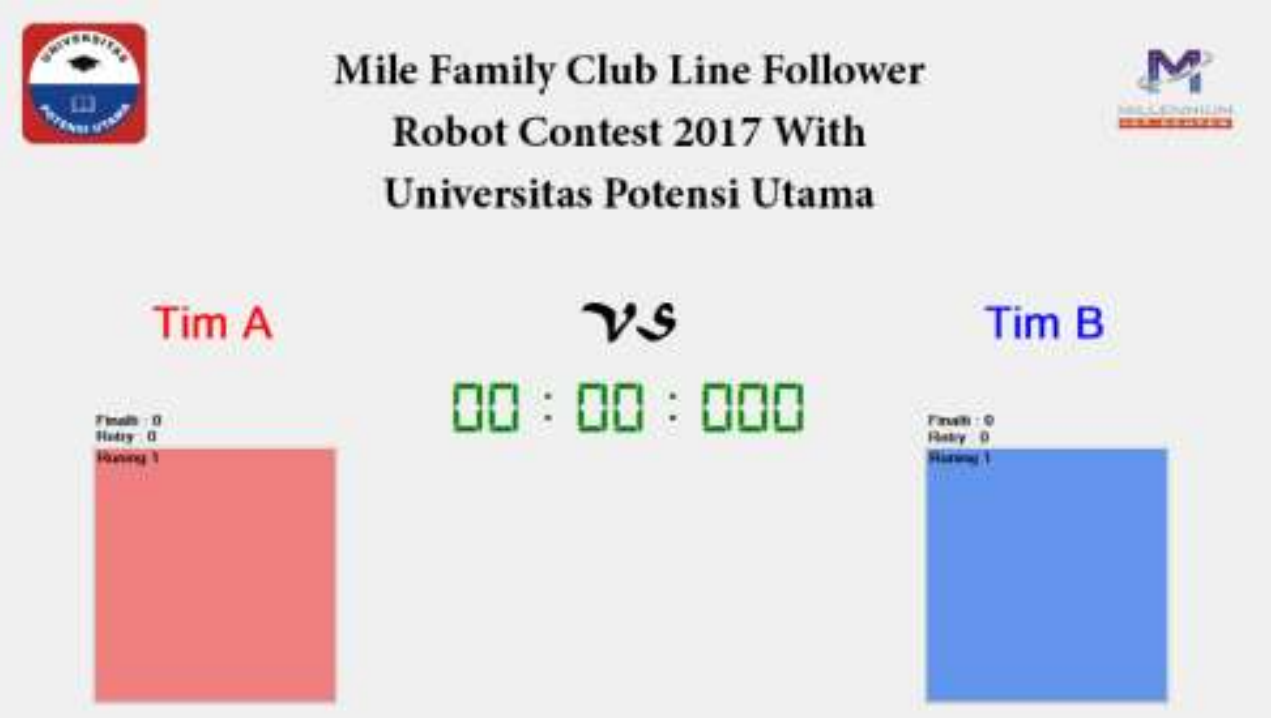

Gambar 7. Tampilan Utama

\subsection{Tampilan Menu Konfigurasi Pertandingan}

Pada tampilan ini dapat melakukan konfigurasi pertandingan yang selanjutnya akan di tampilkan pada halama utama. Tampilan Menu Konfigurasi Pertandingan dapat dilihat pada gambar 8 .

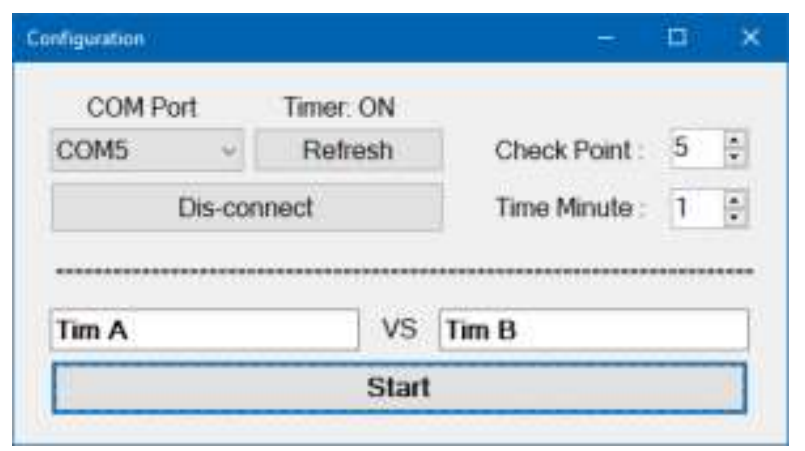

Gambar 8. Tampilan Menu Konfigurasi Pertandingan 


\subsection{Penggabungan Hardware}

Setelah semua rangkaian dan perangkat telah selesai dirancang, kemudian dilakukan penyatuan perangkat dan komponen-komponen yang dibutuhkan agar dapat di uji secara maksimal. Berikut adalah gambar dari keseluruhan hardware ditunjukan oleh gambar 9.

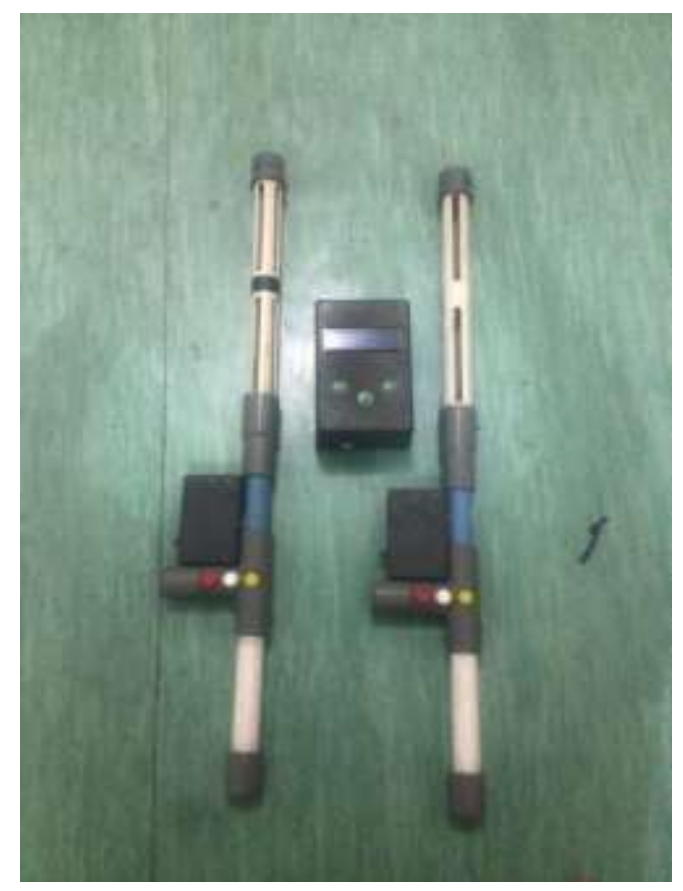

Gambar 9. Keseluruhan Hardware

\subsection{Hasil Pengujian Perangkat Hardware dan Interface}

Setelah perangkat hardware terhubung semuanya. Kemudian memulai koneksi dengan cara memilih port COM selanjutnya klik button Connect pada form konfigurasi. Setelah terhubung maka data dari Bendera Wasit dapat langsung dikirim oleh mikrokontroler yang kemudian ditampilkan oleh software interface pada halaman utama. Apabila tombol satu ditekan maka akan mengirim data check point, tombol dua akan mengirimkan data Retry, dan tombol tiga akan mengirimkan data Finalti. Berikut adalah gambar pada saat software interface Bendera Wasit menampilkan data yang dikirim mikrokontroler, ditunjukkan pada gambar 10. berikut : 


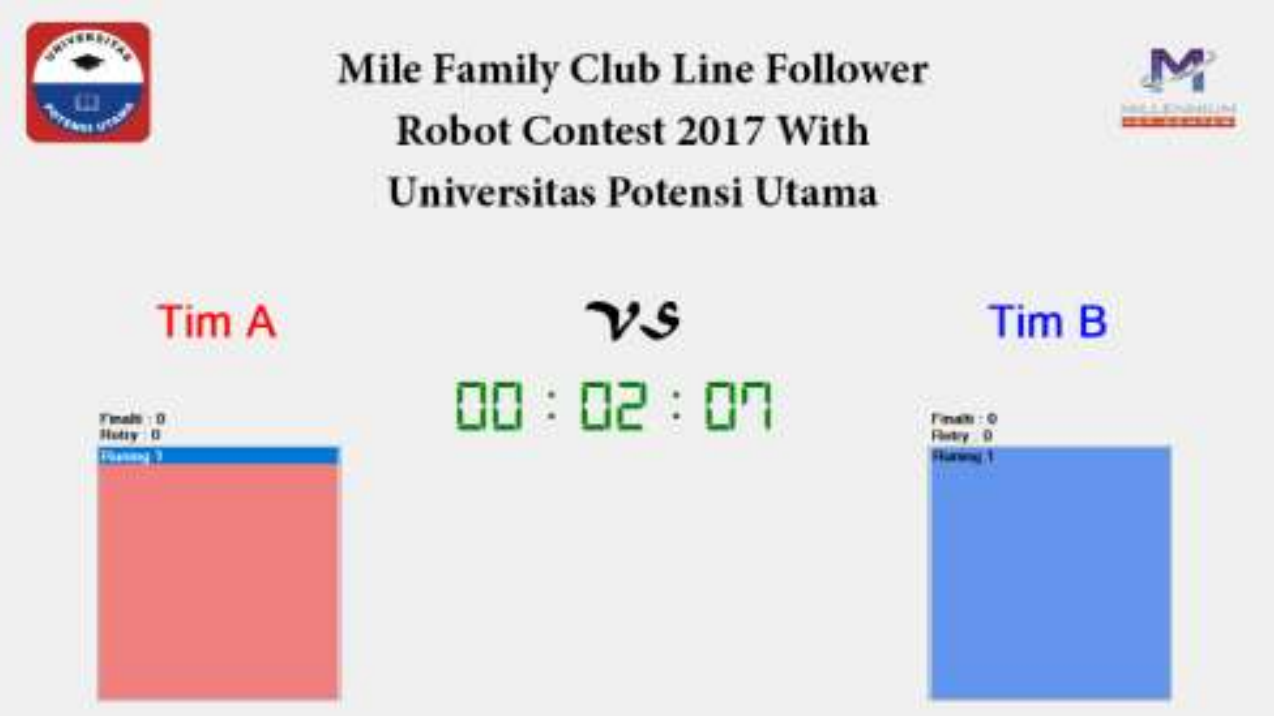

Gambar 10. Tampilan Software Interface saat Penerimaan data

Pada gambar 10 menunjukkan bagaimana proses software interface menerima data yang dikirim oleh Bendera Wasit. Software interface akan terus menerima data secara realtime, selama antara Personal Computer (PC) dan mikrokontroler tidak terputus. Proses penampilan data check point, Retry dan Finalti. Seperti pada gambar 11. :

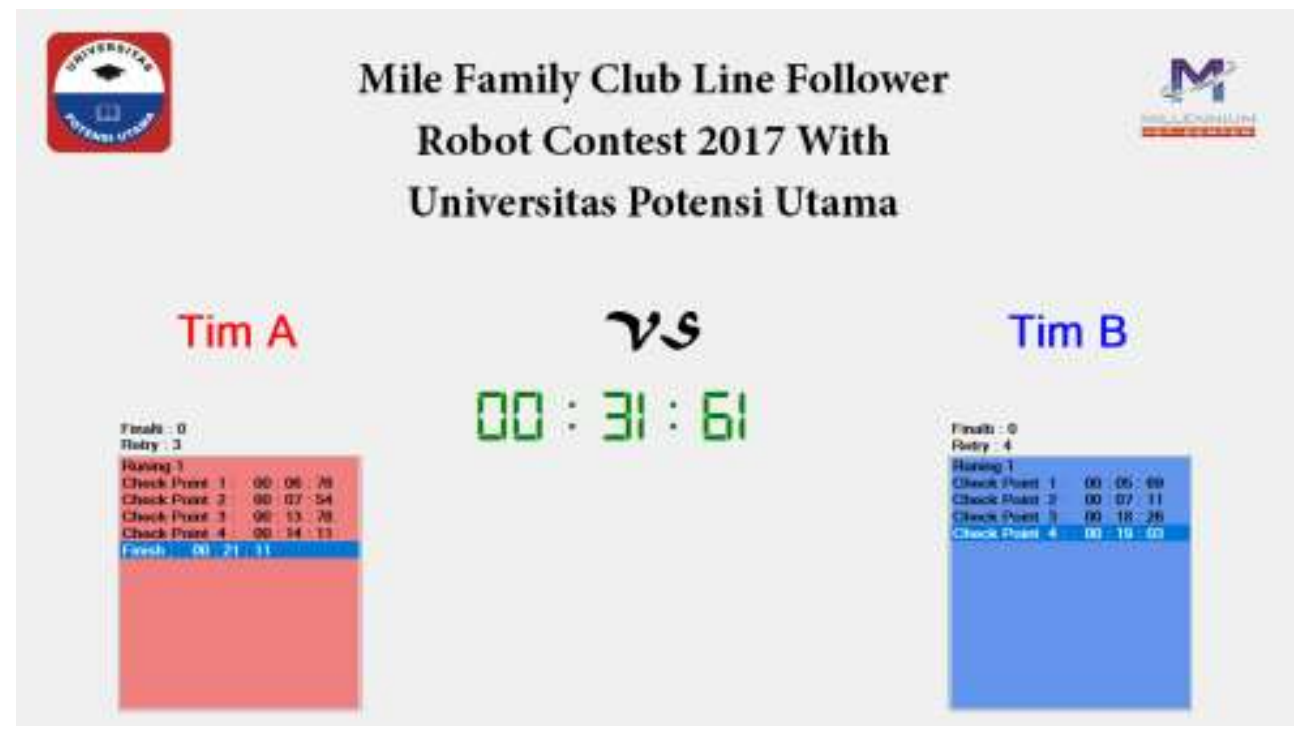

Gambar 11. Tampilan Software Interface Saat menampilkan data pertandingan

Pada gambar 11 menunjukkan bagaimana proses menampilkan data pertandingan. Data tersebut diterima secara realtime selama koneksi antara mikrokontroler dengan Personal Computer $(P C)$ tidak putus. Berikut gambar proses pengiriman data dari Bendera Wasit ke server: 


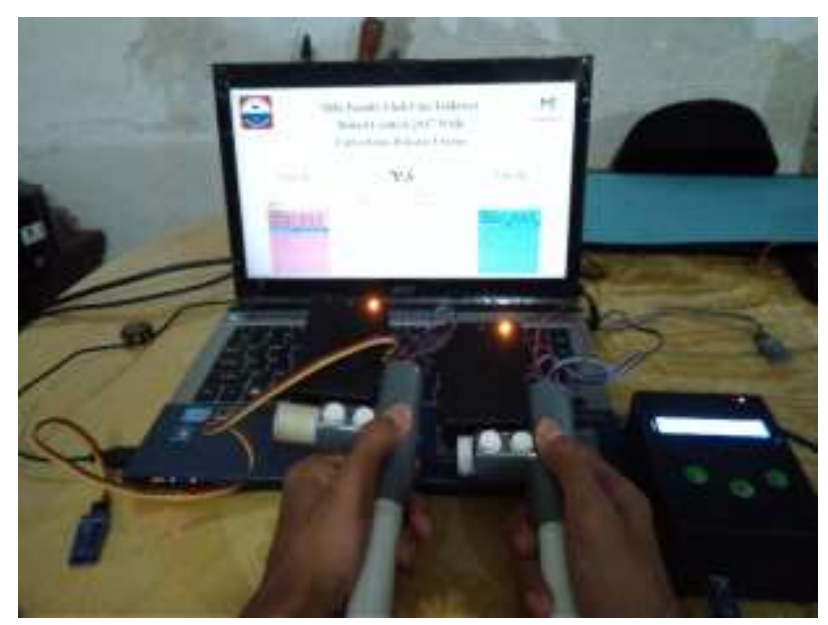

Gambar 12. Tampilan Ketika Proses Pengiriman Data dari Bendera Wasit ke Server

\subsection{Hasil Pengujian Jarak Bluetooth HC-05}

Untuk mengetahui respon Bluetooth HC-05 pada Bendera Wasit terhadap Bluetooth HC-05 pada server. Berdasarkan teori yang didapat, komunikasi Bluetooth HC-05 dapat menjangkau jarak \pm 10 meter. Pada table 1 . berikut adalah hasil pengujian yang telah dilakukan.

Tabel 1. Hasil Pengujian Jarak Bluetooth HC-05

\begin{tabular}{|c|c|c|c|c|c|c|}
\hline \multirow[b]{2}{*}{ No. } & \multirow[b]{2}{*}{ Jarak } & \multicolumn{3}{|c|}{ Pengiriman Data } & \multirow[b]{2}{*}{ Status } & \multirow[b]{2}{*}{ Keterangan } \\
\hline & & Bendera 1 & Bendera 2 & $\begin{array}{c}\text { Bendera } 1 \\
\& \\
\text { Bendera } 2\end{array}$ & & \\
\hline 1 & 1 Meter & $\sqrt{ }$ & $\sqrt{ }$ & $\sqrt{ }$ & Terhubung & Tanpa Halangan \\
\hline 2 & 2 Meter & $\sqrt{ }$ & $\sqrt{ }$ & $\sqrt{ }$ & Terhubung & Tanpa Halangan \\
\hline 3 & 3 Meter & $\sqrt{ }$ & $\sqrt{ }$ & $\sqrt{ }$ & Terhubung & Tanpa Halangan \\
\hline 4 & 4 Meter & $\sqrt{ }$ & $\sqrt{ }$ & $\sqrt{ }$ & Terhubung & Tanpa Halangan \\
\hline 5 & 5 Meter & $\sqrt{ }$ & $\sqrt{ }$ & $\sqrt{ }$ & Terhubung & Tanpa Halangan \\
\hline 6 & 6 Meter & $\sqrt{ }$ & $\sqrt{ }$ & $\sqrt{ }$ & Terhubung & Tanpa Halangan \\
\hline 7 & 7 Meter & $\sqrt{ }$ & $\sqrt{ }$ & $\sqrt{ }$ & Terhubung & Tanpa Halangan \\
\hline 8 & 8 Meter & $\sqrt{ }$ & $\sqrt{ }$ & $\sqrt{ }$ & Terhubung & Tanpa Halangan \\
\hline 9 & 9 Meter & $\sqrt{ }$ & $\sqrt{ }$ & $\sqrt{ }$ & Terhubung & Tanpa Halangan \\
\hline 10 & 10 Meter & $\sqrt{ }$ & $\sqrt{ }$ & $\sqrt{ }$ & Terhubung & Tanpa Halangan \\
\hline 11 & 11 Meter & $\sqrt{ }$ & $\sqrt{ }$ & $\sqrt{ }$ & Terputus & Tanpa Halangan \\
\hline
\end{tabular}


Dari pengujian didapatkan hasil jarak efektif koneksi Bluetooth HC-05 pada Bendera Wasit terhadap Bluetooth HC-05 pada server tanpa halangan adalah \pm 10 meter. Koneksi Bluetooth HC-05 pada Bendera Wasit terhadap Bluetooth HC-05 pada server akan otomatis terhubung pada perangkat yang telah ditentukan apabila server dan Bendera Wasit telah aktifkan dan didalam jangkauan \pm 10 meter.

\subsection{Kelebihan dan Kekurangan Sistem}

Perancangan Bendera Wasit Berbasis Wireless pada Pertandingan Robot ini masih terdapat kekurangan. Berikut beberapa kelebihan dan kekurangan, diantaranya:

\subsubsection{Kelebihan Sistem}

Adapun beberapa kelebihan yang dimiliki Bendera Wasit Berbasis Wireless pada Pertandingan Robot, adalah:

1. Mendapatkan hasil penilaian Pertandingan Robot secara realtime.

2. Mendapatkan hasil penilaian Pertandingan Robot yang akurat.

3. Dapat mempermudah Juri dan Wasit dalam menghitung nilai dari masing - masing peserta Pertandingan Robot

4. Perangkat dirancang seminimalis mungkin sehingga dapat digunakan dengan mudah.

5. Pada software interface, dapat menyimpan hasil pertandingan yang tersimpan secara otomatis.

\subsubsection{Kekurangan Sistem}

Adapun beberapa kekurangan yang dimiliki Bendera Wasit Berbasis Wireless pada Pertandingan Robot, adalah:

1. Untuk menghubungkan antara mikrokontroler server dengan Personal Computer (PC) masih menggunakan kabel usb to serial.

2. Penggunaan Bluetooth $\mathrm{HC}-05$ yang memiliki jarak maksimum koneksi yang hanya sejauh \pm 10 meter.

\section{KESIMPULAN}

Berdasarkan hasil analisa yang dilakukan oleh penulis, Perancangan dan Implementasi Poin Nilai Otomatis berdasarkan Bendera Wasit Berbasis Wireless pada Pertandingan Robot dapat disimpulkan beberapa hal sebagai berikut:

1. Dengan adanya Bendera Wasit Berbasis Wireless dapat mengetahui hasil pertandingan robot secara langsung (realtime).

2. Dengan adanya Bendera Wasit Berbasis Wireless membantu Juri dan Wasit dalam menghitung nilai dari masing - masing peserta Pertandingan Robot.

3. Poin nilai hasil pertandingan sangat bergantung pada nilai input yang dikirim bendera wasit.

4. Jarak maksimum koneksi antara bendera wasit dan server hanya sejauh \pm 10 meter.

\section{SARAN}

Dalam melakukan Perancangan dan Implementasi Poin Nilai Otomatis berdasarkan Bendera Wasit Berbasis Wireless pada Pertandingan Robot ini terdapat beberapa kendala yang dihadapi penulis. Maka penulis akan menyampaikan beberapa saran yang diharapkan pembaca 
dapat memahami prinsip perangkat yang dirancang sehinga dapat mengembangkan skripsi ini. Adapun saran - saran tersebut adalah :

1. Untuk mendapatkan koneksi maksimal yang lebih jauh sebaiknya menggunakan koneksi wireless yang dapat terhubung lebih jauh.

2. Alat ini dapat dikembangkan lagi agar dapat digunakan pada pertandingan pertandingan lainnya.

3. Perangkat ini masih menggunakan kabel usb to serial dalam media komunikasi antara mikrokontroler server dengan Personal Computer (PC), akan lebih peraktis jika komunikasi menggunakan wireless.

\section{UCAPAN TERIMA KASIH}

Penulis mengucapkan terimakasih kepada Universitas Potensi Utama yang telah memberi kesempatan dan dukungan terhadap penelitian ini.

\section{DAFTAR PUSTAKA}

[1] Akhmad Zainuri, Unggul Wibawa, Eka Maulana. 2015. "Implementasi Bluetooth HC-05 untuk Memperbarui Informasi Pada Perangkat Running Text Berbasis Android Kadar Air Tanah Dengan Menggunakan Mikrokontroler Arduino Nano”. Malang: Jurnal EECCIS Vol. 9, No. 2, Desember 2015.

[2] Desiani. 2015. “Aplikasi Sensor Proximity Pada Lengan Robot Sebagai Penyortir Kotak Berdasarkan Ukuran Berbasis Arduino Uno “.http://eprints.polsri.ac.id/1818/. Diakses pada 30 Maret 2017.

[3] Feri Djuandi. 2011. “Arduino-Pengenalan“. http://tobuku.com/index.php /2011/01/08/pengenalan-arduino/. Diakses pada 30 Maret 2017.

[4] Iwan FitriantoRahmad, Vidi Agung Fragastia. 2013. “Navigasi Mobil Robot Rc Berbasis Aplikasi Android“. www.academia.edu/6508669/ NAVIGASI_MOBIL_ROBOT_RC_BERBASIS_APLIKASI_ANDROID. Diakses pada 30 Maret 2017.

[5] Mada Jimmy. 2014. “Komunikasi Arduino dengan VB.NET (serial port)“. madajimmy.com/home/13.../65-komunikasi-arduino-dengan-vbnet-serial-port.pdf. Diakses pada 30 Maret 2017.

[6] Rendy Franata, Oktafri, Ahmad Tusi. 2014. "Rancang Bangun Sistem Irigasi Tetes Otomatis Berbasis Perubahan Kadar Air Tanah Dengan Menggunakan Mikrokontroler Arduino Nano”. Lampung: Jurnal Teknik Pertanian LampungVol. 4, No. 1: 19-26. 